\title{
Cholesterol requirement of juvenile tiger shrimp (Penaeus monodon)
}

\author{
Shyn-Shin Sheen ${ }^{\mathrm{a}, *}$, Ping-Chung Liu ${ }^{\mathrm{b}}$, Shiu-Nan Chen ${ }^{\mathrm{b}}$, \\ Jiann-Chu Chen ${ }^{\mathrm{a}}$ \\ ${ }^{a}$ Department of Aquaculture, National Taiwan Ocean University, Keelung, Taiwan 202, ROC \\ ${ }^{\mathrm{b}}$ Department of Zoology, National Taiwan University, No. 1 Roosevelt Road, Section 4, Taipei, Taiwan 107, \\ ROC
}

Accepted 15 March 1994

\begin{abstract}
The effect of dietary cholesterol on the growth and survival of juvenile tiger shrimp (Penaeus monodon) was tested using semi-purified diets. Twenty-four shrimp per treatment, with an initial mean weight of $268.2 \mathrm{mg}$, were individually housed in black nylon mesh pots in 40-liter aquaria containing $30 \mathrm{ppt}$ seawater. Diets containing $0,0.2,0.4,0.5,0.8$, and $1.0 \%$ supplemental cholesterol were evaluated. The duration of the experiment was 63 days. Shrimp fed diets containing $0 \%$ and $1 \%$ cholesterol had significantly lower weight gain and poorer survival than those fed the other diets. There was no significant difference in weight gain of $P$. monodon fed diets containing $0.2-0.8 \%$ cholesterol. A diet containing $1 \%$ cholesterol had an adverse or toxic effect on $P$. monodon growth.
\end{abstract}

\section{Introduction}

Cholesterol is an important animal sterol which occurs free or in combination with fatty acids in all cells and in blood. It serves as a precursor of a number of compounds, such as sex hormones, adrenal corticoids, bile acids and vitamin D. Most animals can synthesize sterol from acetate, but crustaceans have been shown to be incapable of de novo sterol synthesis from acetate (Teshima and Kanazawa, 1971). Therefore, dietary cholesterol is considered to be essential for good growth and survival of crustaceans. Kanazawa et al. (1971) reported that Penaeus japonicus fed a sterol-free diet had poor growth and survival. Other workers have also demonstrated the necessity of dietary cholesterol for good growth of P. japonicus (Deshimaru and Kuroki, 1974), crayfish, Pacifastacus leniusculus

\footnotetext{
*Corresponding author.
} 
(D'Abramo et al., 1985b) and American lobster, Homarus americanus (Castell et al., 1975; D'Abramo et al., 1984).

Some lack of agreement exists in the reported requirement values of cholesterol for $P$. japonicus. Kanazawa et al. (1971) reported a value of $0.5 \%$ dietary cholesterol for good growth, whereas other researchers have obtained the best growth of $P$. japonicus with diets containing 0.2\% (Shudo et al., 1971) and 2.1\% (Deshimaru and Kuroki, 1974) cholesterol. These contradictory results with $P$. japonicus are considered to be due to differences in the composition of the test diets used. Castell et al. (1975) reported that the optimum level of cholesterol for $H$. americanus was $0.5 \%$. However, D'Abramo et al. (1984) found that a diet containing as low as $0.12 \%$ cholesterol was satisfactory for normal growth of $H$. americanus and no significant difference was observed in the growth of animals fed diets containing 0.19-0.59\% cholesterol. Recently, Kean et al. (1985) re-evaluated the cholesterol requirement for $H$. americanus and reported that $0.25-0.5 \%$ cholesterol was optimal. D'Abramo et al. (1985b) studied the sterol requirement of $P$. leniusculus and found that $0.4 \%$ dietary sterol was associated with the best growth of juvenile crayfish.

The interaction between cholesterol and phosphatidylcholine on the weight gain of $P$. penicillatus and $P$. monodon has been investigated by Chen and Jenn (1991) and Chen (1993), respectively. These studies used three levels of dietary cholesterol $(0,0.5$, and $1 \%$ ) and the results indicated that $0.5 \%$ dietary cholesterol was required. These workers concluded that $0.5 \%$ dietary cholesterol was required for good growth of penaeid shrimp. Therefore, the purpose of this study was to investigate the growth-promoting effects of dietary cholesterol and determine the optimum level for juvenile $P$. monodon.

\section{Material and methods}

Juvenile $P$. monodon were obtained from outdoor ponds of a local commercial shrimp hatchery farm. Animals were held in $58 \times 28 \times 31 \mathrm{~cm}$ aquaria and separated individually by placing them in $12 \times 12 \times 26 \mathrm{~cm}$ cages made from black screen net. Each aquarium contained 8 animals. The aquaria were fitted with under-gravel filters consisted of crushed coral sand. Salinity was maintained at $30 \mathrm{ppt}$ and water temperature ranged between 30 and $33^{\circ} \mathrm{C}$.

There were 6 experimental diets containing $0,0.2,0.4,0.5,0.8$ and $1 \%$ cholesterol ( Table 1). Diets contained $40 \%$ fish meal containing $62 \%$ crude protein as the sole protein source. Lipid was extracted from the fish meal with hot $95 \%$ ethanol $(1: 1, w / v)$ in 4 successive treatments to minimize the contribution of dietary cholesterol. Levels of corn starch and cellulose were changed accordingly to maintain isoenergetic diets. The wheat flour served to bind the diets.

Dry ingredients of the experimental diets were mechanically mixed to insure homogeneity. Distilled water was added and the mixture was blended thoroughly by hand until consistent extrusion was achieved. Diets were cold-extruded through a Nippon Career chopper ( $2.5 \mathrm{~mm}$ die diameter). All experimental diets were dried in a vacuum freeze-dryer (Dura-Dry MP freeze-dryer, model FD-6-55 CMPO, FTS systems, Inc.) for $8 \mathrm{~h}$ until the moisture was reduced to less than $10 \%$. All diets were stored frozen $\left(-20^{\circ} \mathrm{C}\right)$ in air-tight sealed plastic bags until fed to the animals. The experimental diets were analyzed for 
Table 1

Ingredient composition (dry weight \%), proximate analysis and amount of cholestcrol in the experimental diets

\begin{tabular}{|c|c|c|c|c|c|c|}
\hline \multirow[t]{2}{*}{ Ingredient } & \multicolumn{6}{|l|}{ Diets } \\
\hline & A & B & $\mathrm{C}$ & D & $\mathrm{E}$ & $\mathbf{F}$ \\
\hline Cholesterol & 0.0 & 0.2 & 0.4 & 0.5 & 0.8 & 1.0 \\
\hline Corn starch & 21.1 & 20.7 & 20.2 & 20.0 & 19.3 & 18.85 \\
\hline Cellulose & 15.5 & 15.7 & 16.0 & 16.1 & 16.5 & 16.75 \\
\hline $\begin{array}{l}\text { Basal } \\
\text { ingredients }\end{array}$ & 63.4 & 63.4 & 63.4 & 63.4 & 63.4 & 63.4 \\
\hline \multicolumn{7}{|c|}{ Analyzed composition (as fed) } \\
\hline Moisture & 7.9 & 4.7 & 12.0 & 3.2 & 10.8 & 5.2 \\
\hline Crude protein ${ }^{b}$ & 34.1 & 34.3 & 33.7 & 36.0 & 33.9 & 33.7 \\
\hline $\operatorname{Ash}^{\mathrm{b}}$ & 11.7 & 12.0 & 11.9 & 11.8 & 11.9 & 12.4 \\
\hline Crude fat ${ }^{\mathrm{b}}$ & 6.4 & 5.9 & 5.9 & 6.5 & 6.7 & 6.6 \\
\hline Cholesterol $^{b}$ & 0.02 & 0.19 & 0.43 & 0.48 & 0.81 & 0.95 \\
\hline
\end{tabular}

${ }^{a}$ Lipid-extracted fish meal $40 \%$, wheat gluten $5 \%$, dextrin $5 \%$, vitamin mix ${ }^{1} 4 \%$, mineral mix ${ }^{2} 4 \%$, vitamin $\mathrm{E}(500$ $\mathrm{IU} / \mathrm{g}) 0.2 \%$, vilamin A $(500,000 \mathrm{IU} / \mathrm{g}) 0.1 \%$, vitamin D $(500,000 \mathrm{IU} / \mathrm{g}) 0.1 \%$, choline chloride $1 \%$, and lipid $\operatorname{mix}(2: 1$ cod liver oil and corn oil $) 4 \%$.

bxpressed as percent dry weight.

${ }^{1}$ Thiamine $(\mathrm{HCl}) 0.5 \%$, riboflavin $0.8 \%$, niacinamide $2.6 \%, d$-biotin $0.1 \%$, Ca-pantothenate $1.5 \%$, pyridoxine $\mathrm{HCl} 0.3 \%$, folic acid $0.5 \%$, cyanocobalamin $0.1 \%$, inositol $18.1 \%$, ascorbic acid $12.1 \%$, BHT $0.1 \%, p$-aminobenzoic acid $3.0 \%$, and cellufil $60.3 \%$.

${ }^{2}$ Bernhart-Tomarelli modified (Bernhart and Tomarelli, 1966).

proximate composition based on AOAC (1984) methods. Crude protein was determined with a Kjeltec semi-autoanalyzer model 1007 (Tecator, Sweden). Crude lipid was determined by the ether extraction method (Folch et al., 1957). Ash and moisture were determined by the conventional method using a muffle furnace and a $200^{\circ} \mathrm{C}$ oven.

The cholesterol level in the diet and whole body tissue excluding exoskeleton was determined by lipid extraction, saponification and gas-liquid chromatography (GLC). The extracted lipid samples were saponified by refluxing in 50\% ethanolic KOH solution for 40 min. Upon cooling, the samples were diluted with $40 \mathrm{ml}$ distilled water and the unsaponifiable lipids extracted 3 times with 20,30 , and $40 \mathrm{ml}$ of ether. The ether phase was washed several times with distilled water and then evaporated to dryness. The cholesterol was analyzed using GLC (Hitachi 163 instrument, Hitachi Ltd, Japan) equipped with a flame ionization detector. The cholesterol was then separated on a glass column $(3.0 \mathrm{~m} \times 2 \mathrm{~mm})$ packed with $3 \%$ SE-30. The column, injector and detector temperatures were maintained at 275,285 and $285^{\circ} \mathrm{C}$, respectively. Nitrogen was used as the carrier gas. Cholesterol was identified by comparison with the retention time of authentic cholesterol. The magnitude of each peak on the chromatogram was quantified by a Hitachi Chromato-integrator D-2000.

There were 6 dietary treatments consisting of 6 different levels of cholesterol. Each diet was fed to triplicate groups of 8 animals for 63 days. The shrimp were fed to excess twice daily at 10.00 and 17.00. Uneaten feed and other waste material were removed from each cage prior to each feeding period. Individual wet weights were determined every 3 weeks, and recorded to the nearest $0.1 \mathrm{mg}$. Proximate analyses of pooled whole body tissue excluding exoskeleton were conducted at the end of the study. 
Mean wet weights and survival associated with the dietary treatments were compared by a one-way ANOVA (SAS, 1985). If significant differences were indicated at or less than the 0.05 level, Duncan's multiple range test was used to identify significant differences among treatment means (Steel and Torrie, 1980).

\section{Results}

The crude protein and crude lipid content in the experimental diets ranged from 33.7 to $36 \%$ and 5.9 to $6.7 \%$, respectively (dry weight basis) (Table 1). The analysis of cholesterol indicated that the diets formulated to contain $0,0.2,0.4,0.5,0.8$ and $1 \%$ cholesterol actually contained $0.02,0.19,0.43,0.48,0.81$ and $0.95 \%$, respectively.

Growth performance and survival of juvenile $P$. monodon fed the experimental diets for 63 days are shown in Table 2 . At the end of the feeding trial, the mean percent weight gains of juvenile $P$. monodon fed diets containing $0 \%$ and $1 \%$ cholcsterol were significantly lower $(P<0.05)$ than those fed the other treatment diets. There was no significant difference $(P>0.05)$ in percent weight gains of $P$. monodon fed diets containing $0.2,0.4,0.5$, and

Table 2

Mean \pm s.d. ( $\mathrm{mg}$ ) wet weights of initial and final, percent weight gain of juvenile Penaeus monodon and survival rates of the feeding trial

\begin{tabular}{llcll}
\hline $\begin{array}{l}\text { Cholesterol } \\
\text { level }\end{array}$ & Initial weight & Final weight & $\begin{array}{l}\text { Weight gain } \\
(\%)\end{array}$ & $\begin{array}{l}\text { Survival } \\
\text { rates }(\%)\end{array}$ \\
\hline 0.02 & $258 \pm 65$ & $396 \pm 80$ & $101^{\mathrm{a}}$ & $13.3^{\mathrm{a}}$ \\
0.19 & $286 \pm 68$ & $1180 \pm 420$ & $333^{\mathrm{b}}$ & $83.3^{\mathrm{b}}$ \\
0.43 & $261 \pm 59$ & $1082 \pm 390$ & $336^{\mathrm{b}}$ & $86.7^{\mathrm{b}}$ \\
0.48 & $270 \pm 52$ & $1188 \pm 339$ & $348^{\mathrm{b}}$ & $93.3^{\mathrm{b}}$ \\
0.81 & $274 \pm 62$ & $1218 \pm 304$ & $348^{\mathrm{b}}$ & $93.3^{\mathrm{b}}$ \\
0.95 & $295 \pm 69$ & $931 \pm 325$ & $196^{\mathrm{a}}$ & $33.3^{\mathrm{a}}$ \\
\hline
\end{tabular}

Weight gain percentages and survival rates with different superscripts are significantly different $(P<0.05)$.

Table 3

Results of proximate analyses and cholesterol level ( $\mathrm{mg} / \mathrm{g}$ of body weight) of whole body tissue excluding exoskeleton of juvenile Penaeus monodon fed test diets

\begin{tabular}{|c|c|c|c|c|}
\hline \multirow{2}{*}{$\begin{array}{l}\text { Cholesterol } \\
\text { level }\end{array}$} & \multicolumn{4}{|c|}{ Whole body tissue composition (\% dry weight) } \\
\hline & Crude protein & Crude fat & Ash & Cholcstcrol \\
\hline Initial & 76.85 & 10.61 & 12.54 & 0.49 \\
\hline 0.02 & $-{ }^{\mathbf{a}}$ & 12.83 & $-{ }^{a}$ & 0.44 \\
\hline 0.19 & 85.41 & 9.12 & 5.47 & 1.09 \\
\hline 0.43 & 87.33 & 6.71 & 5.96 & 1.03 \\
\hline 0.48 & 85.70 & 5.57 & 5.99 & 0.59 \\
\hline 0.81 & 86.88 & 7.11 & 6.00 & 0.53 \\
\hline 0.95 & 83.53 & 11.30 & 5.16 & 0.61 \\
\hline
\end{tabular}

${ }^{\text {a Missing data. }}$ 
$0.8 \%$ cholesterol. Survival rates of $P$. monodon fed diets containing $0 \%$ and $1 \%$ cholesterol were 13.3 and $33.3 \%$, respectively, whereas survival rates of the remaining groups were in the range of $83.3-93.3 \%$.

Body composition (dry weight basis) and cholesterol content of the whole body tissue of juvenile $P$. monodon fed the different diets are shown in Table 3. P. monodon fed diets containing $0 \%$ and $1 \%$ cholesterol had unexpectedly higher whole body lipid (12.8 and $11.3 \%$, respectively) than those fed the other dietary treatments. The cholesterol content in the whole body tissue increased from 0.44 to $1.09 \%$ and then decreased to $0.61 \%$ with increasing dietary cholesterol levels. $P$. monodon fed the diet containing $1 \%$ cholesterol had lower cholesterol content in their whole body tissue than those fed diets containing 0.2 and $0.4 \%$ cholesterol.

\section{Discussion}

The present study quite clearly indicates that $P$. mondon require a dietary supplement of cholesterol to achieve maximum weight gain and survival. A dietary cholesterol level as low as $\mathbf{0 . 2 \%}$ (dry weight) was found to be satisfactory for good growth and survival of $P$. monodon and feeding a diet without supplemental cholesterol caused poor growth and low survival. D'Abramo et al. (1984) also reported that a dietary cholesterol level as low as $0.12 \%$ (dry weight) in a purified diet and $0.2 \%$ in an unrefined diet was satisfactory for good growth and survival of Homarus sp. In contrast, Castell et al. (1975) reported that a $0.1 \%$ dietary cholesterol level produced inferior growth and survival in $H$. americanus. Kanazawa et al. (1971) reported that $0.5 \%$ dietary cholesterol was optimum for good growth and survival of $P$. japonicus. The optimum level of cholesterol for $P$. monodor (Chen, 1993) and P. penicillatus (Chen and Jenn, 1991) was also found to be $0.5 \%$. The lack of agreement between these results may be due in part to the design of the experimental diets. The supplemental cholesterol levels used in previous experiments on $P$. japonicus (Kanazawa et al., 1971), H. americanus (Castell et al., 1975), $P$. penicillatus (Chen and Jenn, 1993) and $P$. monodon (Chen, 1993) used only two or three levels $(0,0.5$ and $1 \%$ or higher) of cholesterol. The exact cholesterol requirement cannot be determined from these experimental designs. Therefore, based on the results of this study, it would appear that the requirement for crustaceans may be less than the recommended level of $0.5 \%$ cholesterol.

Studies by D'Abramo et al. (1985a) and Teshima and Kanazawa (1983) have shown that digestion and assimilation of dietary cholesterol is affected by dietary lipids and phospholipid. Cholesterol added to a lipid-free diet is almost completely lost in the feces. Adding dietary phospholipids enhances digestibility of sterols. Thus the effective dietary level of cholesterol is very much a function of other dietary factors. With no supplemental lecithin, the $2.1 \%$ dietary cholesterol required for $P$. japonicus reported by Deshimaru and Kuroki (1974) was very likely the level required for the dietary formulation they were using. With no supplemental lecithin and using casein-based diets, Castell et al. (1975) found that 0.1 or $0.2 \%$ was inferior to $0.5 \%$ dietary cholesterol. With varying levels of lecithin supplements, Chen (1993) and Chen and Jenn (1991) found that $0.5 \%$ or higher dietary cholesterol was required for $P$. monodon or $P$. penicillatus. However, with varying levels of lecithin sup- 
plements, Kean et al. ( 1985 ) found $0.25 \%$ cholesterol to be sufficient. With no supplemental lecithin, $0.2 \%$ dietary cholesterol is a minimum requirement for $P$. monodon. Therefore, the physiological effect of phospholipid on the cholesterol requirement of crustaceans needs further investigation.

The results of this study clearly indicate that $P$. monodon require a dietary source of cholesterol. The growth and survival data indicated that $0.02 \%$ dietary cholesterol led to high mortality and poor growth and $0.2 \%$ dietary cholesterol produced growth and survival significantly better than the deficient control diet, but not significantly different from 0.4 , 0.6 or $0.8 \%$ dietary cholesterol. Therefore, the definitive dietary cholesterol requirement must be between 0.2 and $0.8 \%$. However, feeding a level of $1 \%$ dietary cholesterol resulted in an adverse effect on growth in this study. Excessive protein levels may have a detrimental effect on fish and crustaceans (Lim et al., 1979; Sedgwick, 1979) and high lipid levels may also have a detrimental effect on crustaceans (Andrews et al., 1972; Forster and Beard, 1973; Sick and Andrews, 1973; Sheen and D'Abramo, 1991). Mercer (1982) indicated that physiological responses to nutrients are, as a rule, graded. Therefore, for most essential nutrients, there is a characteristic nutrient-response curve which increases to a point and then tend to level off. The high level of dietary cholesterol which caused the negative growth response may be a nutrient-responsc charactcristic rather than toxicity in some instances.

It has been reported that $H$. americanus (Castell et al., 1975) and $P$.japonicus (Kanazawa et al., 1971) fed diets containing high levels of dietary steroids showed inferior growth. D'Abramo et al. (1984) indicated that a dietary cholesterol level greater than $0.5 \%$ for Homarus sp. was unnecessary, because $0.3-0.5 \%$ cholesterol was found in natural prey of juvenile lobsters, such as rock crab and mussels (Teshima and Kanazawa, 1972). In the present study, inferior growth and low survival of $P$. monodon occurred when they were fed the diet containing $1 \%$ cholesterol. Thus, the diets containing excessive levels of cholesterol may cause adverse effects on growth and survival of various prawns. However, the mechanism of this apparent toxic effect is still unknown and further investigation on its metabolism is needed.

\section{Acknowledgements}

This research was supported by the National Science Council (project No. NSC 79-0209B019-10 and NSC 81-0115-C019-01-031B). We would like to thank Mr. C.S. Wang for taking care of the shrimp during the experimental period. We also indebted to Mr. C.C. Chang, Sun-Her Hatchery for supplying the animals.

\section{References}

Andrews, J.W., Sick, L.V. and Baptist, G.J., 1972. The influence of dietary protein and energy levels on growth and survival of penaeid shrimp. Aquaculture, 1: 341-347.

AOAC (Association of Official Analytical Chemists), 1984. Official Methods of Analysis, 14th edn., AOAC, Arlington, VA, $1141 \mathrm{pp}$.

Bernhart, F.W. and Tomarelli, R.M., 1966. A salt mixture supplying the National Research Council estimates of mineral requirements of the rat. J. Nutr., 89: 495-500. 
Castell, J.D., Mason, E.G. and Convey, J.F., 1975. Cholesterol requirements of juvenile American lobsters (Homarus americanus). J. Fish. Res. Board Can., 32: 1431-1435.

Chen, H.Y., 1993. Requirements of marine shrimp, Penaeus monodon, juveniles for phosphatidylcholine and cholesterol. Aquaculture, 109: 165-176.

Chen, H.Y. and Jenn, J.S., 1991. Combined effects of dietary phosphatidylcholine and cholesterol on the growth survival and body lipid composition of marine shrimp, Penaeus penicillatus. Aquaculture, 96: 167-178.

D'Abramo, L.R., Bordner, C.E., Conklin, D.E. and Baum, N.A., 1984. Sterol requirement of juvenile lobsters, Homarus sp. Aquaculture, 42: 13-25.

D'Abramo, L.R., Baum, N.A., Bordner, C.E., Conklin, D.E. and Chang, E.E., 1985a. Diet-dependent cholesterol transport in the American lobster. J. Exp. Mar. Biol. Ecol., 87: 83-96.

D'Abramo, L.R., Wright, J.S., Wright, K.H., Bordner, C.E. and Conklin, D.E., 1985b. Sterol requirement of cultured juvenile crayfish, Pacifastacus leniusculus. Aquaculture, 49:245-255.

Deshimaru, O. and Kuroki, K., 1974. Studies on a purified diet for prawn. II. Optimum contents of cholesterol and glucosamine in the diet. Bull. Jpn. Soc. Sci. Fish., 40: 421-424.

Folch, J., Lee, M. and Stanley, G.H.S., 1957. A simple method for the isolation and purification of total lipids from animal tissue. J. Biol. Chem., 226: 477-509.

Forster, J.R.M. and Beard, T.W., 1973. Growth experiments with the prawn, Palaemon serratus, with fresh and compounded foods. Fish. Invest. Lond., Ser. II, 27, 16 pp.

Kanazawa, A., Tanaka, N., Teshima, S.I. and Kashiwada, K.I., 1971. Nutritional requirements of prawn. II. Requirement for sterols. Bull. Jpn. Soc. Sci. Fish., 37: 211-215.

Kean, J.C., Castell, J.D., Boghen, A.G., D'Abramo, L.R. and Conklin, D.E., 1985. A re-evaluation of the lecithin and cholesterol requirements of juvenile lobster (Homarus americanus) using crab protein-based diets. Aquaculture, 47: 143-149.

Lim. C., Sukhawongs, S. and Pascual, F.P., 1979. A preliminary study on the protein requirements of Chanos chanos (Forskal) fry in a controlled environment. Aquaculture, 17: 195-201.

Mercer, L.P., 1982. The quantitative nutrient-response relationship. J. Nutr., 112: 560-566.

SAS (Statistical Analysis Systems) Institute Incorporated, 1985. SAS/STAT Guide for Personal Computers, version 6 edn. Cary, NC, 378 pp.

Sedgwick, R.W., 1979. Influence of dietary protein energy on growth, food consumption and food conversion efficiency in Penaeus merguiensis de Man. Aqauculture, 16: 7-30.

Sheen, S.-S. and D'Abramo, L.R., 1991. Response of juvenile freshwater prawn, Macrobrachium rosenbergii, to different levels of a cod liver oil/com oil mixture in a semi-purified diet. Aquaculture, 93: 121-134.

Shudo, K., Nakamura, K., Ishikawa, S. and Kitabayashi, K., 1971. Studies on the growth-promoting effects of both squid liver oil and cholesterol. Bull. Tokai Reg. Fish. Res. Lab., 65: 129-137.

Sick, L.V. and Andrews, J.W., 1973. The effect of selected dietary lipids, carbohydrates and proteins on the growth, survival and body composition of Penaeus duorarum. Proc. World Maricult. Soc., 4: 263-276.

Steel, R.G.D. and Torrie, J.H., 1980. Principles and Procedures of Statistics, 2nd edn. McGraw-Hill, New York, NY, 631pp.

Teshima, S. and Kanazawa, A., 1971. Biosynthesis of sterols in the lobster, Panulirus japonicus, the prawn, Penaeus japonicus, and the crab, Portunus trituberculatus. Comp. Biochem. Physiol., 38B: 597-602.

Teshima, S. and Kanazawa, A., 1972. Comparative study on the sterol composition of marine mollusks. Bull. Jpn. Soc. Sci. Fish., 38: 1299-1304.

Teshima, S. and Kanazawa, A., 1983. Digestibility of dietary lipids in the prawn. Bull. Jpn. Soc. Sci. Fish., 49: 963-966. 